\title{
COVID-19 en Centro Penal Costarricense: Estudio Retrospectivo de cohorte
}

\author{
Rafael González Cortes ${ }^{1}$. \\ drgonzalezc1989@gmail.com \\ ${ }^{1}$ Servicios médicos penitenciarios, Ministerio de Justicia y Paz, Costa Rica. Coordinador de los \\ Servicios Médicos de la Unidad de Atención Integral 20 de diciembre de 1979, Docente \\ Universitario, Universidad Latina de Costa Rica, sede Guápiles, Revisor Externo para \\ ScienceDomain, Maestrando Salud Pública, Junta Directiva de Asociación de Médicos del \\ Caribe (AMECARI), creador de @aula_invertida_cr
}

\section{RESUMEN}

Desde diciembre de 2019, el síndrome respiratorio agudo severo por coronavirus 2 (SARS-CoV-2) se ha extendido rápidamente por todo el mundo y en muchos países se implementaron medidas sin precedentes para mitigar sus graves impactos, la población de personas privadas de la libertad no son la excepción.

Materiales y métodos.

Se realiza un estudio retrospectivo, longitudinal, de cohorte, durante 385 días, se plantea como Hipótesis Nula $(\mathrm{H} 0)=$ si se testeara a la totalidad de la población privada de libertad en ese momento, el 66,6\% sería positiva por SARS-CoV-2.

Resultados.

El testeo masivo y oportuno, permitió obtener una muestra con un IC del 95\% y margen de error del 3\%, (218,2-229,8). Donde el 61,1\% resultaron confirmados, lo cual se asemejaba a la propuesta inicial en la Hipótesis Nula.

Discusión.

Para poner en práctica una respuesta oportuna para las poblaciones encarceladas, se deben abordar tres niveles de preparación: se debe retrasar tanto como sea posible la entrada del virus en los entornos penitenciarios; si ya está en circulación, debe controlarse; y las cárceles deben prepararse para hacer frente a una gran carga de morbilidad.

Palabras claves: COVID-19, Brote por 2019-nCoV, Prisiones, Políticas Públicas 


\title{
COVID-19 in the Costa Rican Penal Center: Retrospective Cohort Study
}

\begin{abstract}
Since december 2019, the severe acute respiratory syndrome caused by the second coronavirus (SARS-CoV-2) has rapidly extended all over the world. Many countries have implemented unprecedented measures across their institutions to mitigate it's great impact. Prisons are no exception.

Methods and materials

A retrospective, longitudinal and cohort study is carried upon 385 days. A null hypothesis is presented, stating that $\mathrm{H} 0$ equals $66.6 \%$ positive SARS-CoV-2 cases, if the total inmate population were to be tested.

Results

Massive and opportunistic testing allowed for samples with a 95\% IC and 3\% error margin (218.2-229.8), with $61.1 \%$ confirmed. These results approximate our proposed null hypothesis.

Discussion

In order to implement an opportunistic response for the inmate population, three levels of precaution must be take into account:

First contact with the virus on prison facilities must be delayed as much as possible.

If it's already present, it must be contained.

Prisons must be prepared to handle high morbidity.
\end{abstract}

Keys words: COVID-19, Coronavirus Infections, Prisons, Public Policy

Artículo recibido: 27 marzo 2021 Aceptado para publicación: 30 abril 2021 Correspondencia: drgonzalezc1989@gmail.com Conflictos de Interés: Ninguna que declarar 


\section{INTRODUCCIÓN.}

Desde diciembre de 2019, el síndrome respiratorio agudo severo por coronavirus 2 (SARS-CoV-2) se ha extendido rápidamente por todo el mundo y en muchos países se implementaron medidas sin precedentes para mitigar sus graves impactos, la población de personas privadas de la libertad (ppl) no son la excepción. Se estima que a nivel mundial existe alrededor de 11 millones de ppl, con tasas de encarcelamiento que van desde 698 por 100.000 habitantes en los Estados Unidos hasta tan solo 16 por 100.000 en la República Centroafricana como refiere Franco-Paredes C (2020). Según menciona World Prision Brief (2019), Costa Rica, reporta 19.226 personas privados de libertad, lo que equivale a $374 \mathrm{ppl}$ por cada 100.000 habitantes costarricenses.

Los nuevos patógenos respiratorios altamente transmisibles plantean un nuevo desafío para las poblaciones encarceladas debido a la facilidad con la que se propagan en entornos de congregación según plantea Akiyama MJ, Spaulding AC, Rich JD (2020). El hacinamiento, el saneamiento insuficiente, la ventilación deficiente y la atención médica inadecuada en las cárceles contribuyen a habilitar estas instituciones como cultivo de brotes de enfermedades infecciosas como sostiene Franco-Paredes C (2020).

Barun Mathema, profesor de epidemiología en la Escuela de Salud Pública Mailman de Columbia en Nueva York menciona "La fuerza de la infección puede ser extraordinariamente alta en las cárceles. El más dinámico de estos grupos son las personas que trabajan allí" de acuerdo con Aspinwall C, Neff J (2020).

Abordar la pandemia de COVID-19 en las cárceles requiere cambios en las políticas en toda la sociedad. En el sistema de justicia penal, se necesitan medidas agresivas y proactivas para minimizar la catástrofe que se avecina en las prisiones y cárceles según argumenta Hawks L, Woolhandler S, McCormick D (2020).

En Costa Rica al momento del estudio el Ministerio de Justicia y Paz, reporta un total de 2947 personas privadas de libertad contagiadas por SARS-CoV-2, con 19 lamentables fallecimientos y 659 casos confirmados entre los funcionarios de dicha cartera.

\section{MATERIALES Y MÉTODOS.}

Se realiza un estudio retrospectivo, longitudinal, de cohorte, en el período comprendido entre el 6 de marzo del 2020, hasta el 26 de marzo del 2021 (385 días), en la Unidad de Atención Integral (UAI) 20 de diciembre de 1979, centro ubicado en Punta Riel, del distrito de Roxana, Cantón de Pococí, Provincia de Limón. Una población sujeta a 
estudio de 846 personas, distribuidas de la siguiente manera; 704 personas masculinas privadas de libertad (distribuidas en 10 residencias) con rango de edad de 21 años a 76 años, de los cuales 130 padecen patologías crónicas (68 residentes con hipertensión arterial, 22 residentes con diabetes mellitus tipo 2, 31 residentes asmáticos, 6 residentes inmunosupresos, 2 residentes cardiópatas, 1 residente con enfermedad renal crónica) y 14 son adultos mayores, 104 policías penitenciarios que pernoctan en dicho centro sin distinciones en particular y 38 funcionarios técnicos, administrativos sin distinciones particulares al estudio.

A partir del reporte del primer caso confirmado por SARS-CoV-2 en Costa Rica (6 marzo de 2020), se da inicio a la elaboración de políticas públicas en la Unidad destinadas a la atención de la emergencia ocasionada por la pandemia, las cuales de manera general y categórica menciono; creación de comisión interna de COVID-19 presidida por miembros de distintas áreas técnicas, acercamientos interinstitucionales con entes reguladores y ejecutores de la Salud (Ministerio de Salud, Caja Costarricense del Seguro Social), creación e identificación de espacios de aislamiento para eventuales casos sospechosos y confirmados por COVID-19, elaboración de planes de contingencia ante la emergencia según Lineamientos generales para el manejo del COVID-19 en Centros Penitenciarios en el marco de la alerta sanitaria por Coronavirus (2020) (los cuales incluían demarcación para respetar el distanciamiento social, áreas de lavado de manos, uso obligatorio de cubrebocas como se propone el Lunes 22 de junio, 2020, por el Centro de Prensa, Ministerio de Salud, Costa Rica, impedimento de ingreso de personas externa e internas con síntomas respiratorios acorde a Directriz VGE-006-2020 del Ministerio de Justicia y Paz, toma diaria de temperatura corporal, aislamiento preventivo de personas privadas de libertad que egresaban a prácticas judiciales, internamientos hospitalarios superiores a 24 horas, salidas médicas electivas como se indica en Directriz DVJ-003-2020, Ministerio de Justicia y Paz, traslados de la alimentación diaria, reubicación en residencias de población con patologías crónicas) suspensiones temporales de la visita general y visita íntima a las personas privadas de libertad de acuerdo con Directriz DVJ-002-2020, del Ministerio de Justicia y Paz, regulación en la recepción de encomiendas según se expresa en L-02-2020-DPP, Dirección de la Policía Penitenciaria, Ministerio de Justicia y Paz, identificación de personas privadas de libertad con patologías crónicas que les ocasionaban mayor riesgo 
de vulnerabilidad por COVID-19 y realización de valoraciones extraordinarias para eventuales cambios de medidas cautelares según se declara en Circular 2-2020, del Instituto Nacional de Criminología, Ministerio de Justicia y Paz. Costa Rica, promoción de teletrabajo en perfiles de puestos específicos acorde a la Directriz N0 073-S-MTSS, de la Presidencia de la Republica (2020), producción interna a gran escala de cubrebocas reutilizables (3520 en total) para dotar de las mismas a las personas privadas de libertad, policías penitenciarios y funcionarios, entrega oportuna y constante de insumos de sanitización (alcohol, desinfectantes, soluciones cloradas etc.) campañas extensas de promoción y prevención de la salud en la población meta (charlas, documentos, medios audiovisuales etc.) y elaboración de guías técnicas especificas para el manejo integral de los pacientes sospechosos y confirmados por COVID-19 (incluida rotación del personal de salud para cubrir con atención médica 24 horas del día, los 7 días de la semana mientras existieron casos activos).

A partir del día 17 enero del 2021, se confirma el primer caso de SARS-CoV-2 en la UAI (el contagio del caso índice se sospecha ingreso a través de la visita general realizada el 8 enero de 2021), a partir del mismo se toman las siguientes decisiones; se limita con prontitud el libre tránsito de las personas privadas de libertad para evitar perder el rastro de los nexos epidemiológicos, suspender actividades que generaran aglomeraciones (deportes, procesos, barbería, educación, pulpería, uso obligatorio de cubrebocas, cese de visita general, limitar salidas médicas electivas, reducción de plazas laborales, etc.). Se aumento a 92 espacios de la capacidad inicial para aislar casos confirmados y en 60 espacios de la capacidad inicial para aislar casos sospechosos/contactos directos.

Durante 69 días (período comprendido entre el 17 enero de 2021 hasta 26 marzo de 2021), se logran documentar 151 casos acumulados en personas privadas de libertad (137 confirmados por PCR y 14 confirmados por nexo epidemiológico), todos los casos distribuidos en las distintas residencias (Figura 1). Del total de policías penitenciarios 7 resultaron confirmados por SARS-CoV-2 y 8 funcionarios administrativos. 
Figura 1. Distribución de número de casos confirmados por COVID-19 en el total de residencias

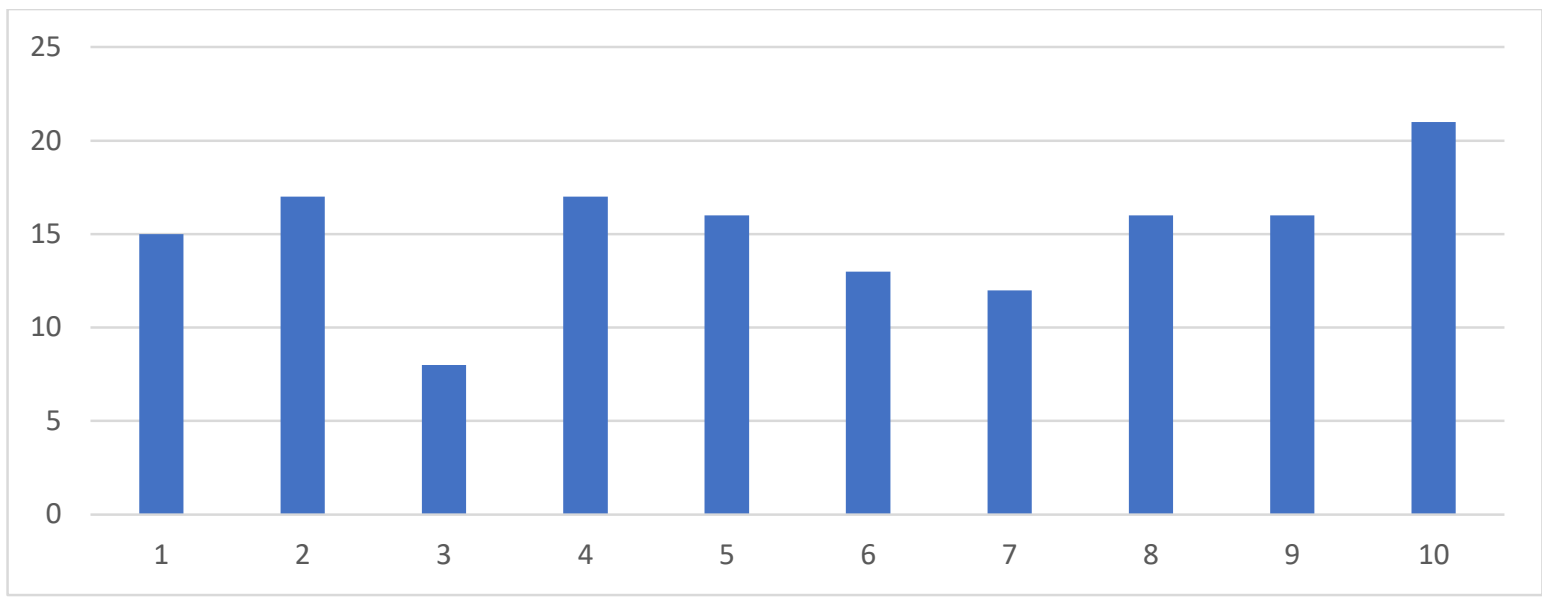

Durante el período mencionado se realizan 3204 valoraciones médicas dirigidas a síntomas compatibles con COVID-19 (incluido Escala de Alerta Temprana (ETA) diaria como se establece en el Lineamiento técnico de manejo para pacientes COVID-19 ingresados en centro especializado, Caja Costarricense del Seguro Social, se aislaron 160 personas privadas de libertad con la definición operativa de caso sospechoso y/o contacto cercano de un caso confirmado, se realizaron 224 hisopados nasofaríngeos Figura 2. Total, de valoraciones médicas, hisopados nasofaríngeos, casos confirmados, casos sospechosos y recuperados, durante el período comprendido del 17 enero 2021 al 26 marzo de 2021.

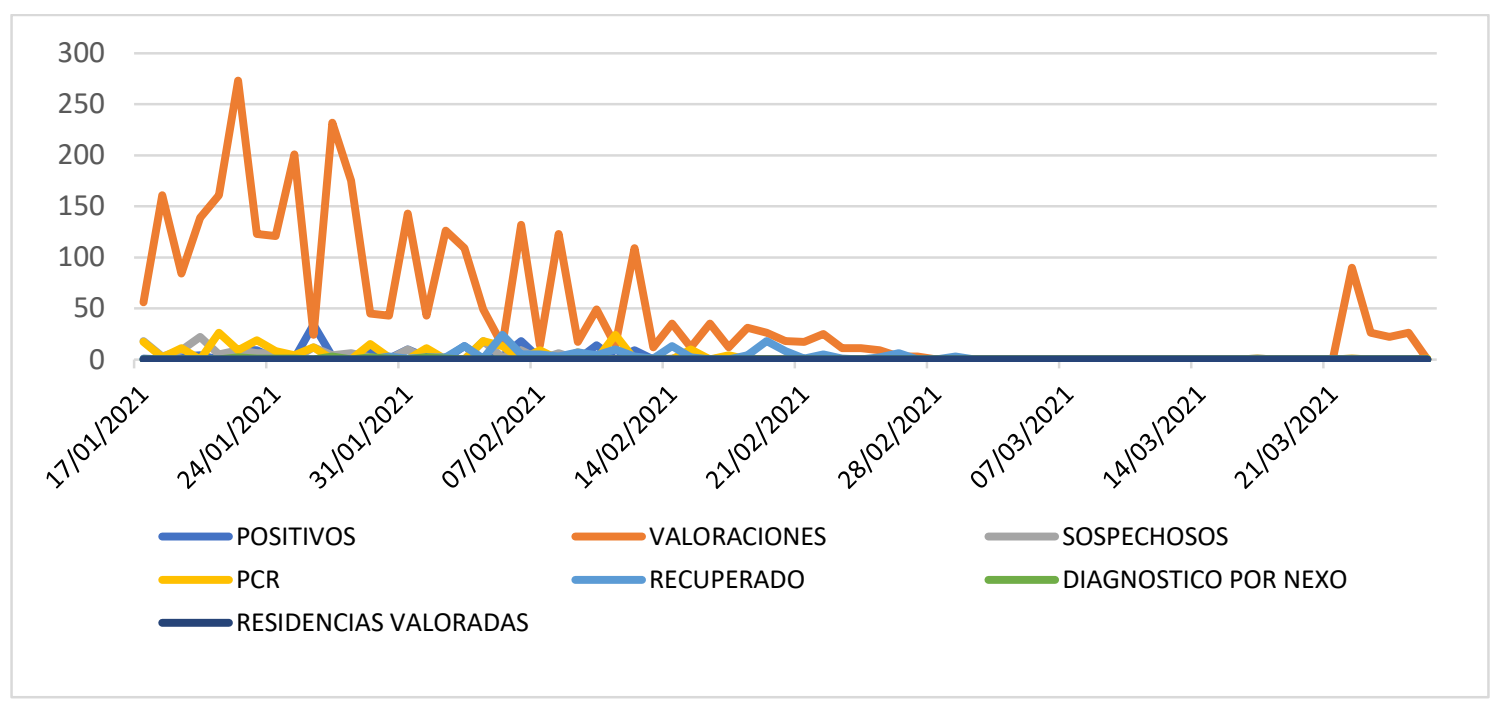

De los 151 casos confirmados, 56 casos al momento del diagnóstico se encontraban asintomáticos, 31 casos presentaron anosmia/disgeusia, 40 casos asociaron cefalea, 3 
casos mencionaron diarrea, 15 casos presentaban tos seca y en 6 de los casos se documento fiebre.

En la primera semana de febrero 2021 y amparados en la versión vigente del Ministerio de Salud, Lineamientos Nacionales para la Vigilancia de la enfermedad COVID-19 LSVS-001. (2021), se acuerda realizar 27 tamizajes a residentes, por medio de un muestreo aleatorio simple, de los cuales 18 fueron positivos por SARS-CoV-2, lo cual significa que el $66,6 \%$ de los tamizajes fueron positivos. Con estos datos, se plantea como Hipótesis Nula $(\mathrm{H} 0)=$ si se testeara a la totalidad de la población privada de libertad en ese momento, el 66,6\% sería positiva por SARS-CoV-2, con un valor de significancia $(\mathrm{p}<0.005)$, con valor $\mathrm{N}=27 \mathrm{y}$ valor $\mathrm{X}=18$, con valor $\mathrm{P}$ del test $=0,16, \pm 1$ desviación estándar, el cual es mayor al nivel de significancia, por tanto; no es posible rechazar H0 y se aceptaba la hipótesis Nula.

Se realizaron 224 hisopados nasofaríngeos, una muestra con un Intervalo de Confianza (IC) del 95\% un margen de error de 3\% (218,2-229,8) donde $\mathrm{N}=704$ (total de la población privada de libertad) de los cuales 137 fueron confirmados por SARS-CoV-2.

\section{RESULTADOS.}

La elaboración oportuna de políticas públicas relacionadas con la pandemia, con base a los cambios y novedades epidemiológicas que se iban presentando, permitió que la Unidad de Atención Integral (UAI) 20 de diciembre de 1979, permaneciera 320 días sin casos confirmados por COVID-19 desde el reporte del primer caso en Costa Rica (6 marzo de 2020) y a pesar de la declaratoria de trasmisión comunitaria emitida por el ente rector desde 2 julio del 2020 según el Ministerio de Salud, Centro de Prensa, además trascurrieron 198 días sin casos desde la aparición del primero en el Sistema Penitenciario Costarricense.

A pesar de la aparición del primer caso en la UAI, el 17 enero del 2021, solamente el 2,5\% del total de policías penitenciarios resultaron confirmados por SARS-CoV-2, y $7,2 \%$ de los funcionarios técnicos y administrativos, todos con una evolución domiciliar y sin complicaciones mayores en su salud.

En lo que respecta a la población privada de libertad, se infiere que el primer caso detectado no correspondía al caso índice y luego de la investigación epidemiológica donde coincide el período de incubación del virus con la aparición exponencial de casos 
confirmados, se sospecha que ingresó a la Unidad posterior a la visita general realizada el 8 enero del 2021.

Con esto y a pesar de poseer un $18,4 \%$ de personas privadas de libertad portadoras de enfermedades crónicas (52,3\% hipertensos, 23,8\% asmáticos, 16,9\% diabéticos los de mayor prevalencia) las cuales confieren una mayor morbi-mortalidad por COVID-19, asociado a 1,9\% de personas adultas mayores (> 65 años), el control oportuno de sus patologías crónicas, utilización obligatoria de cubrebocas, promoción y prevención de la salud, asegurar el aislamiento de los casos confirmados y sus conglomerados (aumento de capacidad inicial de un 67,3\% para aislar casos confirmados y $25 \%$ de la capacidad inicial para aislar los sospechosos/contactos cercanos), asociado a la valoración médica oportuna, permitió que ninguno de los 151 casos acumulados requirieran hospitalizaciones y/o se documentaran fallecimientos asociados a COVID-19.

El testeo masivo y oportuno (224 muestras) durante el brote, permitió obtener una muestra con un IC del 95\% y margen de error del 3\%, (218,2-229,8) de la población ( $\mathrm{N}=704)$. Por tanto; del total de hisopados nasofaríngeos en 137 muestras se detectó SARS-CoV-2, o sea $61,1 \%$ resultaron confirmados, lo cual se asemejaba a la propuesta inicial en la Hipótesis Nula $(66,6 \%$ de la población total se había contagiado de la enfermedad, \pm 1 desviación estándar) en la parte más álgida de casos activos, se podía inferir que aproximadamente 429,44 personas privadas de libertad ya habían sido contagiadas por SARS-CoV2. Por lo cual, era razonable pensar que aproximadamente en la primera semana de febrero 2021, se había logrado alcanzar la inmunidad de rebaño deseada (Figura 3).

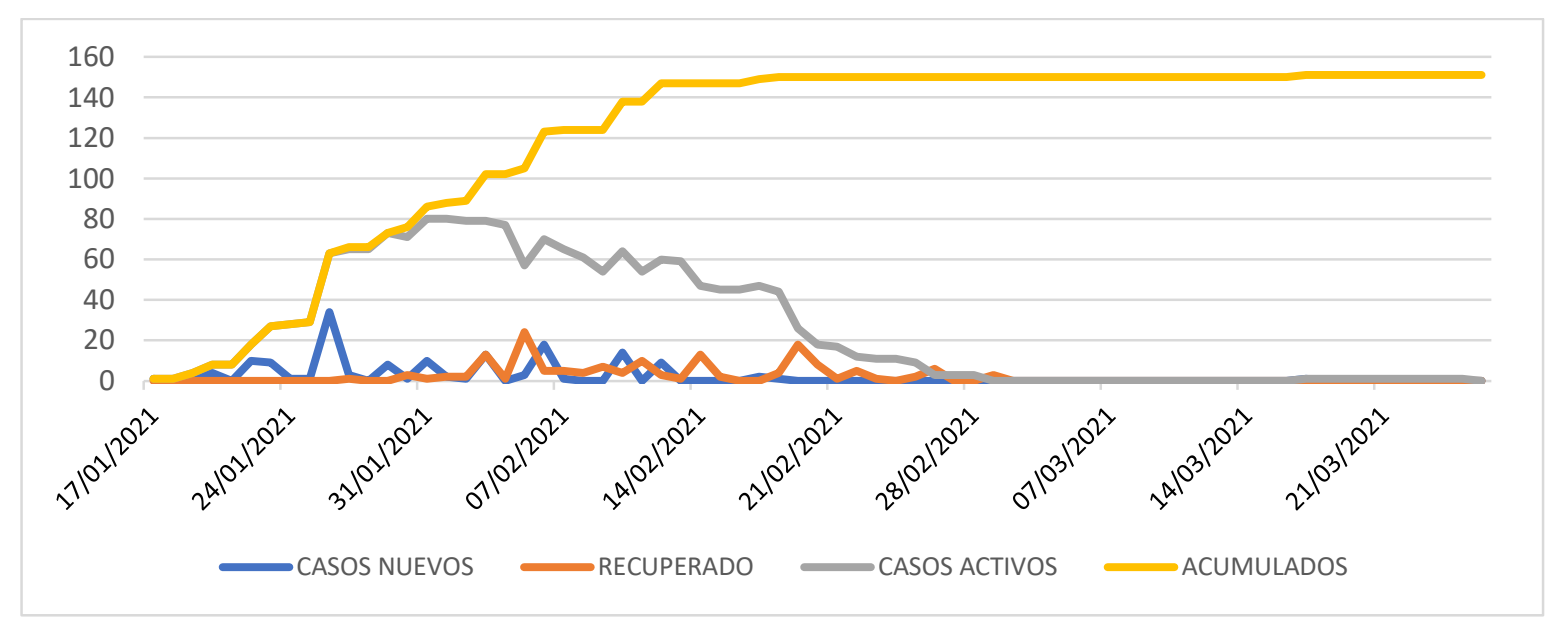

Figura 3. Se logra observar como a partir de la primera semana de febrero 2021, existe un descenso continuo en el número de casos activos, compatibles con la Hipótesis Nula propuesta. 
De los 151 casos confirmados, y una media de Incidencias Acumuladas (IA) por residencias del 21,6\%, al momento del diagnóstico: el 37\% de los casos se encontraban asintomáticos, 20,5\% presentaron disgeusia y anosmia, 26,4\% únicamente presentaron cefalea, en $3,9 \%$ de los casos se documento fiebre, $1,9 \%$ presentaron diarrea y $9,9 \%$ presentaron tos seca.

\section{DISCUSIÓN.}

Para poner en práctica una respuesta oportuna para las poblaciones encarceladas, se deben abordar tres niveles de preparación: se debe retrasar tanto como sea posible la entrada del virus en los entornos penitenciarios; si ya está en circulación, debe controlarse; y las cárceles deben prepararse para hacer frente a una gran carga de morbilidad según Akiyama MJ, Spaulding AC, Rich JD (2020).

A pesar de poseer una población con alta prevalencia de comorbilidades asociadas, y edades avanzadas, que según Onder G, Rezza G, Brusaferro S (2020), aumenta el riesgo de mortalidad independientemente de la infección por COVID-19, se postula que uno de los factores asociados a la nula mortalidad por COVID-19, tiene que ver con el control adecuado de sus patologías preexistentes.

Asociado a ello, una revisión sistemática y metaanálisis propuesto por Yanes-Lane $\mathrm{M}$, Winters N, Fregonese F, Bastos M, Perlman-Arrow S, Campbell JR, Menzies D (2020), encontraron que posterior a la evaluación de casi todos los residentes de un municipio durante la ola inicial de la epidemia en Italia, aproximadamente la mitad de todos los participantes (50\%) con COVID-19 estaban asintomáticos en el momento de la prueba y al final del seguimiento aproximadamente el $40 \%$ permanecían asintomáticos, aun así los estudios virológicos indican que las personas asintomáticas excretan cantidades similares de virus que las personas sintomáticas. El uso obligatorio de cubrebocas previo y durante el brote parecen haber jugado un papel fundamental en el buen desenlace del mismo, esto acorde a lo encontrado por Li T, Liu Y, Li M, Qian X, Dai SY (2020), donde indican que el estudio sugiere que usar un cubrebocas puede potencialmente disminuir el número de reproducción viral en una población general. Por lo cual se prevé que los casos leves tenían un aclaramiento viral temprano, y como sugiere Liu Y et al. (2020) una mayor carga viral podría estar asociada con resultados clínicos graves. 
Con lo anterior mencionado resultó muy razonable aceptar la Hipótesis Nula propuesta, la cual indicaba que el $66,6 \%$ de la población estaba o ya había estado contagiada por SARS-CoV-2, eso explicaría el descenso regular de casos nuevos ya que, y como menciona Rodríguez Hernández C, Sanz Moreno L (2020), en el caso de COVID-19, el nivel requerido para lograr una inmunidad de rebaño se ha estimado generalmente en torno al $70 \%$.

Respecto a los síntomas encontrados en los casos confirmados (cefalea 26,4\%, 20,5\% presentaron disgeusia, anosmia y $9,9 \%$ presentaron tos seca como los más frecuentes) estos difieren con los encontrados en un metaanálisis realizado por Zhu J, Ji P, Pang J, Zhong Z, Li H, He C, Zhang J, Zhao C. (2020), donde documentaron Fiebre (80,4\%), fatiga $(46 \%)$, tos $(63,1 \%)$ como los más frecuentes, esto también podría deberse a la disminución circulante de la carga viral, así como el limitado número de casos estudiados.

\section{AGRADECIMIENTOS}

A la señora viceministra de Gestión Estratégica y al comando de atención de la emergencia por COVID-19, a la Jefatura Nacional de Servicios de Salud por su apoyo y confianza, a la mesa de salud de la Comisión Municipal de Emergencias, al director general del centro penal por su colaboración, a la policía penitenciaria del centro penal, a mí equipo de trabajo en el área de salud, al resto de personeros de salud del Ministerio de Justicia y Paz por su labor incesante.

\section{BIBLIOGRAFÍA}

Franco-Paredes C, Jankousky K, Schultz J, Bernfeld J, Cullen K, Quan NG, Kon S, Hotez P, Henao-Martínez AF, Krsak M. COVID-19 in jails and prisons: A neglected infection in a marginalized population. PLoS Negl Trop Dis. 2020 Jun 22;14(6):e0008409. doi: 10.1371/journal.pntd.0008409. PMID: 32569274; PMCID: PMC7307724

World Prision Brief Data, Costa Rica, Central America (2019). Recuperado de: https://www.prisonstudies.org/country/costa-rica.

Akiyama MJ, Spaulding AC, Rich JD. Flattening the Curve for Incarcerated Populations - Covid-19 in Jails and Prisons. N Engl J Med. 2020 May 28;382(22):2075-2077. doi: 10.1056/NEJMp2005687. Epub 2020 Apr 2. PMID: 32240582; PMCID: PMC7398586.. 
Aspinwall C, Neff J. These prisons are doing mass testing for COVID-19-and finding mass infections. Accessed June 15, 2020. Recuperado de: https://www.themarshallproject.org/2020/04/24/these-prisons-are-doing-masstesting-for-covid-19-and-finding-mass-infections.

Hawks L, Woolhandler S, McCormick D. COVID-19 in Prisons and Jails in the United States. JAMA Intern Med. 2020 Aug 1;180(8):1041-1042. doi: 10.1001/jamainternmed.2020.1856. PMID: 32343355.

LS-SI-006. (2020). Lineamientos generales para el manejo del COVID-19 en Centros Penitenciarios en el marco de la alerta sanitaria por Coronavirus. Versión: 006 Sexta edición, Fecha de elaboración: 2 de diciembre del 2020, Aprobado por: Ministerio de Salud- Dirección de Servicios de Salud.

Lunes 22 de junio, 2020. Mascarillas obligatorias en varios servicios y comercios a partir del sábado 27 de junio. Centro de Prensa. Ministerio de Salud. Costa Rica. Recuperado de: https://www.ministeriodesalud.go.cr/index.php/centro-deprensa/noticias/741-noticias-2020/1731-mascarillas-obligatorias-en-variosservicios-y-comercios-a-partir-del-sabado-27-de-junio

Adenda \#1 a la Directriz VGE-006-2020, 04 de mayo del 2020, Por Tanto; NOVENO. Acuerdo N0 312-P, fecha 16 de julio del 2019. Ministerio de Justicia y Paz. Costa Rica.

Directriz DVJ-003-2020, Autorización de Salidas Médicas, 03 abril del 2020, Acuerdo Ejecutivo número 180-P, del 25 febrero del 2019, publicado en la Gaceta N0 56. Ministerio de Salud. Costa Rica.

Directriz DVJ-002-2020, del 20 de marzo del 2020, Lineamientos sobre la visita de los centros penitenciarios, Ministerio de Justicia y Paz. Costa Rica.

L-02-2020-DPP, 24 de marzo 2020, Regulación de las filas y proceso de recibido de las encomiendas, Memorándum 298, Dirección de la Policía Penitenciaria, Ministerio de Justicia y Paz. Costa Rica.

Circular 2-2020, 11 de marzo de 2020, Valoración y Ejecución de acuerdos para cambios de nivel durante la alerta por COVID-19, sesión ordinaria 5497, Articulo 44. Instituto Nacional de Criminología, Ministerio de Justicia y Paz. Costa Rica. 
Directriz N0 073-S-MTSS, del 9 marzo del 2020, Presidencia de la Republica, San José, Costa Rica, martes 10 de marzo del 2020, Alcance $\mathrm{N}^{0} 41$ a la Gaceta $\mathrm{N}^{0} 47$, http://www.mtss.go.cr/elministerio/biblioteca/documentos/Directriz\%20073-SMTSS.pdf

Lineamiento técnico de manejo para pacientes COVID-19 ingresados en centro especializado para atención de pacientes COVID-19, Caja Costarricense del Seguro Social, Gerencia Médica, Dirección de Desarrollo de Servicios de Salud. Código: LT.GM.DDSS-AAIP-270420. Recuperado de: https://www.ccss.sa.cr/web/coronavirus/assets/materiales/personal/lineamientos/ 233.pdf

LS-VS-001. (2021) Lineamientos Nacionales para la Vigilancia de la enfermedad COVID-19. Versión: 19 Décimo novena edición. Ministerio de Salud- Despacho Ministerial. Costa Rica. Recuperado de: https://www.ministeriodesalud.go.cr/sobre_ministerio/prensa/docs/ls_vs_001_ve rsion_19_vigilancia_covid19_31032021.pdf

Jueves 2 de julio, 2020, Ministerio de Salud declara transmisión comunitaria de forma precautoria en la GAM, Centro de Prensa. Ministerio de Salud. Costa Rica. Recuperado de: https://www.ministeriodesalud.go.cr/index.php/centro-deprensa/noticias/741-noticias-2020/1752-ministerio-de-salud-declaratransmision-comunitaria-de-forma-precautoria-en-la-gam

Onder G, Rezza G, Brusaferro S. Case-Fatality Rate and Characteristics of Patients Dying in Relation to COVID-19 in Italy. JAMA. 2020;323(18):1775-1776. doi:10.1001/jama.2020.4683.

Yanes-Lane M, Winters N, Fregonese F, Bastos M, Perlman-Arrow S, Campbell JR, Menzies D. Proportion of asymptomatic infection among COVID-19 positive persons and their transmission potential: A systematic review and meta-analysis. PLoS One. 2020 Nov 3;15(11):e0241536. doi: 10.1371/journal.pone.0241536. PMID: 33141862; PMCID: PMC7608887.

Li T, Liu Y, Li M, Qian X, Dai SY. Mask or no mask for COVID-19: A public health and market study. PLoS One. 2020 Aug 14;15(8):e0237691. doi: 10.1371/journal.pone.0237691. PMID: 32797067; PMCID: PMC7428176. 
Liu Y, Yan LM, Wan L, Xiang TX, Le A, Liu JM, Peiris M, Poon LLM, Zhang W. Viral dynamics in mild and severe cases of COVID-19. Lancet Infect Dis. 2020 Jun;20(6):656-657. doi: 10.1016/S1473-3099(20)30232-2. Epub 2020 Mar 19. PMID: 32199493; PMCID: PMC7158902.

Rodríguez Hernández C, Sanz Moreno L. Inmunidad frente a SARS-CoV-2: caminando hacia la vacunación [Immunity against SARS-CoV-2: walking to the vaccination]. Rev Esp Quimioter. 2020 Dec;33(6):392-398. Spanish. doi: 10.37201/req/086.2020. Epub 2020 Sep 11. PMID: 32935536; PMCID: PMC7712341.

Zhu J, Ji P, Pang J, Zhong Z, Li H, He C, Zhang J, Zhao C. Clinical characteristics of 3062 COVID-19 patients: A meta-analysis. J Med Virol. 2020 Oct;92(10):19021914. doi: 10.1002/jmv.25884. Epub 2020 Jun 24. PMID: 32293716; 